\title{
BİREYSEL KAYNAKLAR, İŞİ BİÇIMMLENDİRME VE İŞE TUTULMA İLIŞKİSINDE BAŞA ÇIKMANIN ARACILIK ROLÜ
}

(D) Nejat BASIM ${ }^{\mathrm{a}}$

\author{
Murat GÜLER ${ }^{b}$
}

Metin OCAKc

\begin{abstract}
Özet
Çalışanların işlerine tutulmaları, iş taleplerine karşı sahip oldukları kaynaklardan ve işlerini biçimlendirebilme düzeylerinden etkilenmektedir. Bu çalışmada İş Talepleri-Kaynakları Modelinde belirtilen bireysel kaynaklar, işi biçimlendirme ve işe tutulma ilişkisinde, çalışanların başa çıkma becerilerinin aracılık rolü araştırılmıştır. Bu amaçla temel benlik değerlendirmeleri, başa çıkma, işi biçimlendirme ve işe tutulma ölçekleri kullanılarak 276 çalışandan anket yöntemiyle toplanan verinin nicel analizleri yapılmış ve araştırmanın hipotezleri test edilmiştir. Elde edilen bulgular olumlu benlik değerlendirmesinin işe tutulma üzerindeki etkisinde başa çıkmanın ve işi biçimlendirmenin anlamlı bir biçimde sıralı aracılık rolünün olduğunu göstermiştir. Çalışanların sahip oldukları kişisel kaynaklarının, başa çıkma yeteneklerini ve işi biçimlendirmelerini etkilemesi yoluyla nihai olarak işe tutulmalarını olumlu yönde etkilediği değerlendirilmiştir. Elde edilen bulgular yazın bağlamında tartışılarak İş Talepleri-Kaynakları Modelinin başa çıkma kavramıyla geliştirilebileceği önerilmiştir.
\end{abstract}

Anahtar Kelimeler: Temel benlik değerlendirmeleri, Başa çıkma, İşi biçimlendirme, İşe tutulma, İş taleplerikaynakları modeli

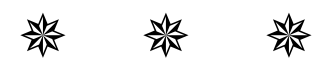

\section{MEDIATING ROLE OF COPING ON THE RELATIONSHIP AMONG INDIVIDUAL RESOURCES JOB CRAFTING AND JOB ENGAGEMENT}

\begin{abstract}
Employees' engagement is effected by the resources they have to fulfill job demands and their level of job crafting. In this study, we investigated the mediating role of employees' coping skills on the relationship among individual resources, job crafting, and engagement in the context of job demands and resources. For this purpose, the research hypotheses were tested by applying quantitative analyses of the data collected from 276 employees using the questionnaire method through the core self-evaluations, coping with stress, job engagement, and job crafting scales. The findings have shown that coping and job crafting have a significant
\end{abstract}

\footnotetext{
a Prof. Dr., Başkent Üniversitesi, İktisadi ve İdari Bilimler Fakültesi, İşletme Bölümü, nbasim@baskent.edu.tr

bDoç. Dr., Niğde Ömer Halisdemir Üniversitesi, İktisadi ve İdari Bilimler Fakültesi, İşletme Bölümü, murat_guler@ohu.edu.tr

c Doç. Dr., Toros Üniversitesi, İktisadi ve İdari Bilimler Fakültesi, İşletme Bölümü, metin.ocak@toros.edu.tr

Makale Geliş Tarihi: 29.09.2021, Makale Kabul Tarihi: 21.12.2021
} 
sequential mediating role on the effect of positive core self-evaluations on job engagement. It has been evaluated employees' personal resources positively effect job engagement through coping abilities and job crafting. The findings were discussed in the context of the literature and it has been suggested that the job demands-resources model can be expanded with the concept of coping.

Keywords: Core self-evaluations, Coping, Job crafting, Job engagement, Job demands-resources model

$$
\text { 资资 }
$$

\section{Giriş}

Çalışanların işlerine yönelik olumlu tutumlara sahip olmaları ve işe tutulmaları, iş bağlamının kendilerinin yerine getirmelerini beklediği talepleri karşlayabilmeleri için yeterli kaynaklara sahip olmalarıyla doğrudan ilişkilidir (Schaufeli ve Bakker, 2004; Bakker ve Demerouti, 2007; Taris ve Schaufeli, 2016). Söz konusu kaynak talep dengesinin bireysel ve örgütsel sonuçlarını inceleyen İş Talepleri-Kaynakları Modeline göre, çalışanların, işin beklentilerini yerine getirmek için gereken kaynakları artırarak ve bununla birlikte işin taleplerini azaltarak veya düzenleyerek iş bağlamını kendi inisiyatifi ile biçimlendirebilmesi, çalışanların işe tutulmalarını olumlu etkiyebilecek biçimde aracılık rolü üstlenebilmektedir (Lichtenthaler ve Fischbach, 2019; Tims ve Akkemans, 2010; Tims ve Bakker, 2010; Tims, Bakker ve Derks, 2012). Bununla birlikte İş Talepleri-Kaynakları Modeli kapsamında değinilmeyen, önemli bir bireysel değerlendirme süreci ve bunu temsil eden bir kavram olan başa çıkma, bu çalışma kapsamında incelenerek söz konusu model içerisindeki işlevi açığa çıkarılmaya çalışılmıştır. İnsanlar karşılaştığı zorlu iş ve yaşam problemleriyle başa çıkabilmek için, önce durumun kendileriyle olan ilişkisini, ardından sahip olduğu kaynakların yeterli olup olmadığını değerlendirirler. Bireyin zorlayıcı durumlar karşısında sahip olduğu kaynakların yeterli veya fazla olduğuna yönelik bir değerlendirme yapması, durumun üstesinden gelmeye yönelik başa çıkma algısının artmasına yol açarak, problemleri başarılı bir şekilde çözmesini ve bireysel iyi oluşunu olumlu yönde etkilemektedir (Jones ve Bright, 2001; Lazarus, 1993; Weiss ve Cropanzano, 1996). Bireyin başa çıkma algısı ve yetkinliği temel olarak bireyin sahip olduğu kişisel kaynaklarına ve bunların en başında da temel benlik değerlendirmesine dayanmaktadır (Kammayer-Mueller vd., 2009).

Ne var ki İş Talepleri-Kaynakları Modelinin güncel halinde (Bakker ve Demerouti, 2017; Tummers ve Bakker, 2021) kaynaklar-işi biçimlendirme-işe tutulma ilişkisinin açıklanmasında başa çıkma kavramı model içerinde incelenmemektedir. Yazında ulaşabildiğimiz iki ayrı çalışma (Ângelo \& Chambel, 2014; Searle, ve Lee, 2015) dışında başa çıkma kavramının ana akım İş Talepleri-Kaynakları Modeli yazınında yeterince dikkat çekmediği anlaşılmaktadır. Çalışanların işi biçimlendirebilme düzeylerinin, belirli ölçüde kendi yaptıkları işin bağlamıyla ilgili problemleri çözebilme ve işi yapma biçimini değiştirmeyle ilgili sorunların üstesinden gelebilme becerisini, kısaca başa çıkma yetkinliğini gerektirdiği ve sahip olunan kaynaklar ile söz konusu kaynakların harekete geçirilmesi arasında bir rolünün olduğunu

| 1742 | düşünüyoruz. Bu yaklaşımla, mevcut çalışmada İş Talepleri-Kaynakları Modelinde öne sürülen bireysel kaynaklar - işi biçimlendirme - işe tutulma ilişkisinde başa çıkma yetkinliğinin aracılık rolü araştırılarak, çalışanların sahip olduğu kaynaklarının onları işlerini biçimlendirmeye nasıl yönlendirdiği ve işe tutulmalarını nasıl etkilediğinin anlaşılmasına katkı sağlanmaya çalışılmıştır. 


\section{A. KAVRAMSAL ÇERÇEVE}

İş Talepleri-Kaynakları Modeli (Schaufeli ve Bakker, 2004; Bakker ve Demerouti, 2007; Bakker ve Demerouti, 2017; Crawford, LePine ve Rich, 2010; Taris ve Schaufeli, 2016; Tummers ve Bakker, 2021) iş bağlamının çalışan bireyden beklediği talepler karşısında sağladığı ve çalışanın sahip olduğu kaynakların denge durumunun olumlu olması durumunun çalışanın işe tutulmasına ve iyi oluşuna, olumsuz olmasının ise çalışanın tükenmesine ve dolayısıyla olumsuz iş ve bireysel sonuçlara yol açacağını öne sürmektedir. Modele göre iş bağlamının tüm özellikleri iki ana kategoriye ayrılmaktadır. İşin olumsuz, zorlayıcı tüm yönleri "iş talepleri”, destekleyici olumlu yönleri "iş kaynakları" olarak kategorize edilmektedir. Burada söz konusu olan kaynaklar sadece iş ortamında sağlanan kaynaklarla sınırlı değildir. Modelin ilk dönem çalışmalarında (Schaufeli ve Bakker, 2004; Bakker ve Demerouti, 2007) örgütsel kaynaklara odaklanılmış olsa da zamanla gelişen model içerisinde iş talepleri karşısında çalışanların psikolojik ve fizyolojik olarak sahip olduğu bireysel kaynakları da değerlendirilmeye başlanmıştır (Schaufeli ve Taris, 2014). Mazzetti ve arkadaşlarının yaptığı meta analiz çalışmasının sonuçları bireysel kaynakların, örgütsel kaynaklardan daha yüksek düzeyde işe tutulmayla ilişkili olduğunu göstermektedir (Mazzetti vd., 2021). Bireylerin öz yeterliliğini, öz saygısını, nevrotikliğini ve kontrol odağını birleşik bir yapı altında temsil eden temel-benlik değerlendirmesi iş talepleri karşısında çalışanların sahip olduğu önemli bireysel kaynaklardan biri olarak görülmektedir (Tims ve Akkerman, 2017; Bipp, Kleingeld ve Ebert, 2019). Temel benlik değerlendirmesi olumlu olan çalışanların, iş talepleri karşısında psikolojik hazır oluşu (Kahn, 1990) daha yüksek düzeyde olacağından fiziksel, bilişsel ve duygusal enerjilerini iş rollerine daha yüksek düzeyde verebilirler (Rich, Lepine ve Crawford, 2010).

Bunun yanında, çalışanın iş ortamının fiziksel (görev) yapısını, sosyal ilişkilerini ve işiyle ilgili bilişsel değerlendirmesini biçimlendirebilme inisiyatifinin olması, sahip olduğu kaynakları işe tutulma yönünde daha etkili kullanılmasını sağlayabilmektedir (Tims ve Bakker, 2010; Bakker, Tims, Derks, 2012; Tims, Bakker ve Derks, 2012). İşi biçimlendirme (job crafting) olarak ifade edilen bu olgu, çalışanın işin kaynaklarını artırabilmesi yanında, iş taleplerini de kontrol altında tutulabilmesi, sınırlandırılabilmesi durumunu göstermektedir. Yönetim tarafından yukarıdan aşağıya doğru yürütülen iş tasarımı kavramından farklı olarak, işi biçimlendirme çalışanın kendi motivasyonu ve inisiyatifiyle harekete geçmesini, işi kendi iradesiyle en iyi şekilde gerçekleştirebileceği biçimde düzenleyebilme serbestisini ve yeteneğini ifade etmektedir (Wrzesniewski ve Dutton, 2001). Yapılan görgül araştırmalar işi biçimlendirmenin iş kaynakları ve işe tutulma ilişkisinde aracılık rolü bulunduğunu, çalışanların kaynakları arttıkça daha fazla işlerini biçimlendirdiklerini ve daha fazla işlerine tutulduklarını (Lichtenthaler ve Fischbach, 2019; Tims ve Akkemans, 2010) ve daha yüksek performans sergilediklerini (Tims, Bakker ve Dark, 2014) göstermektedir.

Bireysel kaynakları yüksek olan çalışanlar stresli ve zorlu durumlarla karşılaştıklarında uyaranı değerlendirirken başa çıma yeteneklerini daha olumlu değerlendirerek zorlu durumla daha etkili biçimde başa çıkabilirler. Stresle başa çıkma, insanla çevresi arasındaki etkileşim sonucunda farklı etkenlerle bozulan bireysel denge durumunu tekrar eski uygun haline geri getirme çabasıdır (Lazarus, 1993). Başa çıkma yetkinliği, karşılaşılan durumunun zorlu talepleri karşında, kişinin sahip olduğu tüm kaynakların ve yeteneklerin mevcut problemin üstesinden gelebilme ve tekrar denge durumuna 
dönülebilmesine yeterli olduğuna dair algıyı ve inancı ifade etmektedir. Başa çıkma süreci, bireyin iki aşamalı zihinsel değerlendirmesiyle şekillenmektedir. Bu zihinsel değerlendirmenin ilk aşamasında karşılaşılan durumun bir tehdit, kayıp veya bir meydan okuma mı olduğu gözden geçirilir. İkinci aşamada sahip olunan kaynak ve yetkinliklere göre stres kaynağının üstesinden gelinip gelinemeyeceği değerlendirilir. Bu değerlendirmelerin sonucuna göre farklılaşan başa çıkma yöntemleri uygulanır (Jones ve Bright, 2001; Lazarus, 1993; Weiss ve Cropanzano, 1996). Bu yaklaşıma göre, iş bağlamının zorlu talepleri karşısında çalışanın sahip olduğu kaynakların yeterliliğine dair algısı, işyerindeki başa çıkma yeteneğinin düzeyini belirleyecektir. Dolayısıyla başa çıkma yeteneklerinin artması çalışanın karşılaştığı iş taleplerinin üstesinden gelme inancını artırabilir ve daha fazla inisiyatif alarak işi biçimlendirmesini olumlu yönde etkileyebilir. Önceki görgül araştırmalar sonucunda, iş kaynakları ile işe tutulma ilişkisinde proaktif başa çıkmanın anlamlı aracılık rolünün bulunduğu (Ângelo ve Chambel, 2014), iş talepleri ve işe tutulma ilişkisinde proaktif başa çıkmanın anlamı biçimde düzenleyicilik etkisinin bulunduğu (Searle ve Lee, 2015) bildirilmektedir. Bu bağlamda mevcut çalışmada, İş TalepleriKaynakları Modeline dayanarak yazında öne sürülen kaynaklar ve işe tutulma ilişkisinde işi biçimlendirmenin aracılık rolünün bulunduğu modelin (Tims ve Akkerman, 2017), başa çıkmanın da içinde sıralı aracılık rolüyle bulunduğu şekliyle genişletilebileceği düşüncesi öne sürülebilir. Bu önermeyi incelemeye yönelik olarak oluşturulan araştırma hipotezleri aşağıda ve araştırma modeli Şekil 1 'de sunulmuştur.

H.1: Olumlu benlik değerlendirmelerinin işe tutulma üzerindeki etkisinde işi biçimlendirmenin aracılık rolü vardır.

H.2: Olumlu benlik değerlendirmelerinin işe tutulma üzerindeki etkisinde başa çıkmanın aracılık rolü vardır.

H.3: Olumlu benlik değerlendirmelerinin işe tutulma üzerindeki etkisinde başa çıkmanın ve işi biçimlendirmenin siralı aracılık rolü vardır.

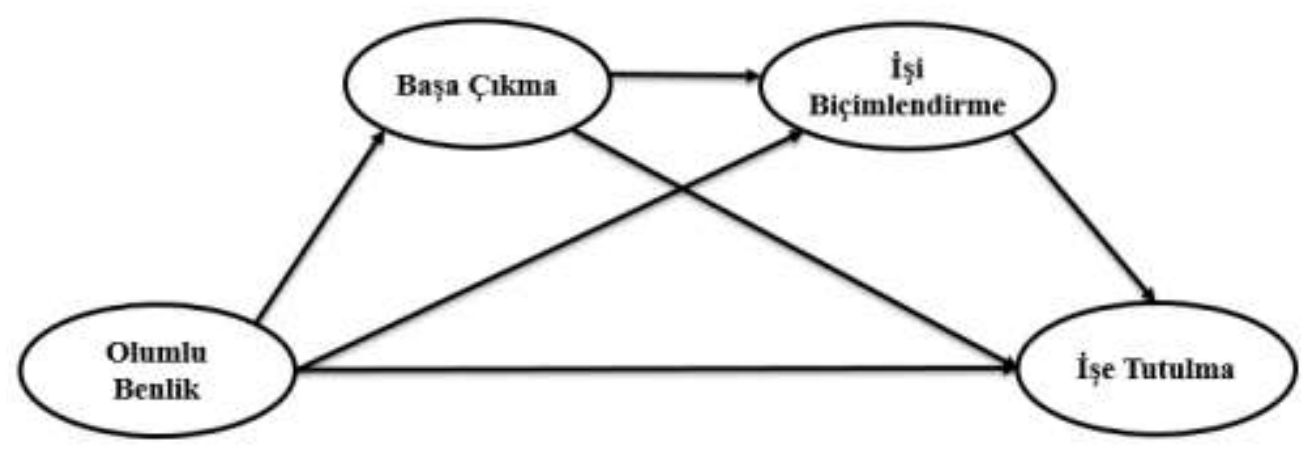

Şekil 1. Araştırma Modeli

\section{B. ARAŞTIRMANIN YÖNTEMI}

\section{Katılımcilar}

Araştırmanın katılımcıları, yazarlardan biri tarafından yürütülen “Uzlaştırmacı Eğitimi”ne katılan ve farklı işlerde çalışan bireylerden oluşan kolayda bir örneklemdir. Söz konusu eğitim sonunda verilen 
elektronik anket bağlantısı yoluyla katılımcılardan anket formunu internet üzerinden doldurmaları istenmiştir. Araştırmaya katılım gönüllülük esasına göre ve anonim olarak gerçekleştirilmiştir. Katılımcıların 132'si (\% 47,5) kadın, 146'sı (\%52,5) erkek olmak üzere toplam 276 kişidir ve yaş ortalamaları $37,8(\mathrm{ss}=8,9)^{\prime}$ dir.

\section{2. Ölçüm Araçları}

Temel Benlik Değerlendirmeleri: Judge ve arkadaşları (2003) tarafından geliştirilen ve Şeşen (2010) tarafından Türkçeye uyarlanan Temel-Benlik Değerlendirmeleri Ölçeği katılımcıların olumlu benlik değerlendirmelerini ölçmek amacıyla kullanılmıştır. Toplam 12 maddelik Likert tipi ölçeğin 6 maddesi olumlu benlik değerlendirmelerini ölçmektedir. Uyarlama çalışmasında ölçeğin tek boyutlu yapısının Cronbach Alfa güvenilirlik değeri $\alpha=, 85$ olarak raporlanmıştır (Şeşen, 2010). Mevcut araştırmada olumlu benlik boyutunun güvenilirlik değeri $\alpha=, 71$ olarak bulunmuştur.

Stresle Başa Çıkma: Katılımcların başa çıkma düzeylerini ölçmek üzere Cohen, Kamarck ve Mermelstein (1983) tarafından geliştirilmiş olan Likert tipi Algılanan Stres Ölçeğinin başa çıkmayı ölçen 8 maddesi kullanılmıştır. Ölçeğin Türkçeye uyarlama çalışmaları önceki araştırmalarda yapılmıştır (Baltaş, Atakuman ve Duman, 1998; Örücü ve Demir, 2008; Eskin vd., 2013). Uyarlama çalışmasında ölçeğin 10 maddelik formu için Cronbach Alfa güvenilirlik katsayısı $\alpha=.82$ (Eskin vd., 2013), mevcut araştırmada 8 maddelik formu için $\alpha=, 83$ olarak bulunmuştur.

İşi Biçimlendirme: Katılımcıların işlerini biçimlendirme düzeylerinin ölçülmesi amacıyla Slemp ve Vella-Brodrick (2013) tarafından geliştirilen, Likert tipi İş Biçimlendirme Ölçeğinin 5 maddelik Görev Biçimlendirme alt ölçeği yazarlar tarafından Türkçeye uyarlanarak kullanılmıştır. Orijinal ölçeğin Görev Biçimlendirme boyutu için Cronbach Alfa güvenilirlik katsayısı $\alpha=, 87$, mevcut araştırmada ise $\alpha=, 75$ olarak bulunmuştur.

İşe Tutulma: Katılımcıların işe tutulma düzeylerinin ölçülmesi amacıyla Schaufeli, Bakker ve Salanova (2006) tarafından geliştirilen, Eryılmaz ve Doğan (2012) ile Özkalp ve Meydan (2015) tarafından Türkçeye uyarlanan Utrecht İşe Tutulma Ölçeğinin, Güler, Çetin ve Basım (2019) tarafından önerilen Likert tipindeki 6 maddelik kısa formu (UWES-6) kullanılmıştır. Uyarlama çalışmasında ölçeğin 6 maddelik formu için Cronbach Alfa güvenilirlik katsayısı $\alpha=, 93$ (Güler vd., 2019) mevcut araştırmada ise $\alpha=, 90$ olarak bulunmuştur.

Ölçüm araçlarının her biri için ve birlikte oluşturdukları ölçüm modelinin yapısal geçerliliğini incelemek üzere doğrulayıcı faktör analizi yapılmıştır. Elde edilen model uyum iyilik değerleri Tablo 1'de sunulmuştur. Ölçüm araçları içerisinde sadece başa çıkma ölçeğinde iki çift maddeye yönelik iyileştirme yapılmıştır. Bunun sonrasında ulaşılan uyum iyilik değerlerine göre her bir ölçeğin ve tüm ölçeklerin içinde bulunduğu ölçüm modelinin $\left(\mathrm{X}^{2} / \mathrm{sd}=1,79, \mathrm{CFI}=0,93\right.$, SRMR $\left.=0,06 \mathrm{RMSEA}=0,05\right)$ iyi uyum kriterlerini karşıladığı ve ölçümün yapısal olarak geçerli olduğu (Hu \& Bentler, 1999) değerlendirilmiştir. 
Tablo 1. Doğrulayıcı Faktör Analizleri Uyum İyilik Değerleri

\begin{tabular}{lllllll}
\hline & $\mathbf{X}^{\mathbf{2}}$ & sd & $\mathbf{X}^{2} / \mathbf{s d}$ & CFI & SRMR & RMSEA \\
\hline 1. Olumlu Benlik Değerlendirmesi & 23,70 & 9 & 2,63 & 0,94 & 0,05 & 0,08 \\
2. Başa Çıkma & 154,66 & 20 & 7,73 & 0,83 & 0,086 & 0,15 \\
Başa Çıkma(iyileştirilmiş) & 65,80 & 18 & 3,65 & 0,94 & 0,06 & 0,09 \\
3. İşi Biçimlendirme & 13,96 & 5 & 2,79 & 0,96 & 0,05 & 0,08 \\
4. İşe Tutulma & 9,82 & 6 & 1,64 & 0,99 & 0,01 & 0,05 \\
5. Ölçüm Modeli & 472,43 & 264 & 1,79 & 0,93 & 0,06 & 0,05
\end{tabular}

$\chi 2 /$ sd= ki kare serbestlik derecesi oranı, CFI= Karşılaştırmalı uyum indeksi, SRMR=Standardize edilmiş ortalama hatların karekökü, RMSEA= Yaklaşık hataların ortalama karekökü

\section{BULGULAR}

Araştırma değişkenlerinin betimleyici istatistikleri kapsamında ortalamaları ve standart saplamaları, normal dağılım gösterip göstermediklerini incelemek için ise çarpıklık ve basıklık değerleri hesaplanmıştır. Elde edilen çarpıklık ve basıklık değerlerine göre araştırma verisinin normal dağıldığı değerlendirilmiştir (Tabachnick ve Fidell, 2013). Değişkenler arasındaki ikili ilişkileri görmek için Pearson korelasyon analizi yapılmış ve elde edilen analiz sonuçları Tablo 2'de sunulmuştur. İşe tutulma olumlu temel benlik değerlendirmesi ile $(\mathrm{r}=, 48, \mathrm{p}<, 01)$, başa çıkma ile $(\mathrm{r}=, 46, \mathrm{p}<, 01)$, işi biçimlendirme ile $(\mathrm{r}=, 43, \mathrm{p}<$,01) aynı yönde ve anlamlı biçimde ilişkili bulunmuştur, Ayrıca işe tutulma yaşla da aynı yönde ilişkili $(\mathrm{r}=, 20, \mathrm{p}<.01)$ bulunmuştur. İşi biçimlendirmenin olumlu temel benlik değerlendirmesi ile $(\mathrm{r}=, 43, \mathrm{p}<, 01)$ ve başa çıma ile $(\mathrm{r}=, 42, \mathrm{p}<, 01)$ aynı yönde ve anlamlı biçimde ilişkili olduğu görülmüştür. Başa çıkma ise temel benlik değerlendirmesi ile $(r=, 64, p<, 01)$ ve yaş ile $(r=, 21, p<, 01)$ aynı yönde anlamlı biçimde ilişkili bulunmuştur. Cinsiyetin erkek olması araştırma değişkenleri içinde sadece başa çıkma ile düşük düzeyde aynı yönde $(r=, 16, p<, 01)$ ilişkili bulunmuştur.

Tablo 2. Değişkenlerin Betimleyici İstatistikleri ve Korelâsyon Katsayıları

\begin{tabular}{|c|c|c|c|c|c|c|c|c|c|c|}
\hline Değişkenler & Ort. & ss & Çarpıklık & Basıklık & (1) & (2) & (3) & (4) & (5) & (6) \\
\hline 1.Cinsiyet $(1 \mathrm{~K}, 2 \mathrm{E})$ & - & - & - & - & - & & & & & \\
\hline 2. Yaş & 37,8 & 9,2 & 0,8 & 1,7 &, $15^{*}$ & & & & & \\
\hline 3.Olumlu Temel Benlik & 3,9 & 0,5 & $-0,3$ & 0,1 & 03 & .11 & $(, 71)$ & & & \\
\hline 4. Başa Çıkma & 3,5 & 0,6 & $-0,3$ & 0,5 &, $16^{* *}$ &, $21^{* *}$ &, $64^{* *}$ & $(, 83)$ & & \\
\hline 5. İşi Biçimlendirme & 3,4 & 0,6 & $-0,1$ & 0,6 & 06 & 10 & $43^{* *}$ & $42^{* *}$ & $(, 75)$ & \\
\hline 6. İşe Tutulma & 4,2 & 0,9 & 0,1 & $-0,4$ & .03 &, $20^{* *}$ & $48^{* *}$ & $46^{* *}$ & $43^{* *}$ & $(, 90)$ \\
\hline
\end{tabular}

${ }^{*} \mathrm{p}<.05,{ }^{* *} \mathrm{p}<.01, \mathrm{n}=276$, Cronbach Alfa güvenilirlik değerleri parantez içinde verilmiştir 
Araştırma hipotezlerini test etmek amacıyla işe tutulmanın bağımlı değişken, olumlu temel benlik değerlendirmesinin bağımsız değişken, başa çıkma ve işi biçimlendirmenin aracı değişkenler olarak incelendiği regresyon analizi yapılmıştır. Bu analiz için PROCESS 3.2 (Hayes, 2018) IBM SPSS eklentisinden faydalanılmıştır. Hesaplanan doğrudan ve özellikle dolaylı etkilere yönelik regresyon katsayılarının anlamlılığını değerlendirmek için (\%95) güven aralığı yöntemi ve 5000 yeniden örnekleme (bootstrap) kullanılmıştır (Shrout ve Bolger 2002, Preacher ve Hayes 2008). Yeniden örneklemeli güven aralığı yöntemine göre hesaplanan alt limit ve üst limit değerleri arasında "0" değerinin olmaması incelenen etki değerinin anlamlı olduğunu göstermektedir. Analiz sonuçlarına göre öncelikle hesaplanan doğrudan etkileri gösteren bulgular Tablo 3'te ve araştırma modeli üzerinde Şekil 2.'de sunulmuştur.

Tablo 3. Regresyon Analizi Sonuçları (Doğrudan Etkiler)

\begin{tabular}{|c|c|c|c|c|c|c|c|c|c|}
\hline \multirow{3}{*}{$\begin{array}{l}\text { Bağımlı Değişken } \\
\text { Bağımsız Değişkenler }\end{array}$} & \multirow{2}{*}{\multicolumn{3}{|c|}{$\begin{array}{r}\text { Başa Çıkma } \\
\text { Yeniden } \\
\text { Örnekleme } \\
\% 95 \text { GA }\end{array}$}} & \multirow{2}{*}{\multicolumn{3}{|c|}{$\begin{array}{r}\text { İşi Biçimlendirme } \\
\text { Yeniden } \\
\text { Örnekleme } \\
\% 95 \text { GA }\end{array}$}} & \multicolumn{3}{|c|}{ İşe Tutulma } \\
\hline & & & & & & & & \multicolumn{2}{|c|}{$\begin{array}{r}\text { Yeniden } \\
\text { Örnekleme } \\
\text { \%95 GA }\end{array}$} \\
\hline & B & Alt & Üst & B & Alt & Üst & B & Alt & Üst \\
\hline Sabit & ,37 &,- 73 & 82 & $1,21^{* *}$ & 66 & 1,77 &,- 06 &,- 84 & ,72 \\
\hline Cinsiyet (1K, 2E) &, $13^{*}$ & ,03 & ,24 & 01 &,- 12 & 15 &,- 08 &,- 26 & 11 \\
\hline Yaş &, $01^{* *}$ & 01 & 01 & 01 &,- 01 & 01 &, $01^{*}$ & 01 & ,02 \\
\hline Olumlu Temel Benlik &, $68^{* *}$ &, 58 & ,78 &, $30^{* *}$ & 14 & 46 & $43^{* *}$ & ,20 & 65 \\
\hline Başa Çıkma & & & &, $25^{* *}$ & 11 & 40 &, $29^{* *}$ & ,09 &, 50 \\
\hline İşi Biçimlendirme & & & & & & &, $35^{* *}$ & ,18 &, 51 \\
\hline $\mathrm{R}^{2}$ & & 43, & & & ,22 & & & 33, & \\
\hline
\end{tabular}

Yapılan regresyon analizlerinde katılımcıların cinsiyet ve yaşlarının bağımlı değişkenler üzerindeki etkisi kontrol edilmiştir. Cinsiyetin erkek olmasının başa çıkma üzerinde, $(B=, 13, p<.05)$ olumlu yönde etkisinin olduğu, yaşın ise başa çıma $(B=, 01, p<, 01)$ ve işe tutulma üzerinde $(B=, 01$, $\mathrm{p}<.01$ ) olumlu yönde etkisinin olduğu tespit edilmiştir. Araştırmanın temel değişkenlerinin etkileri incelendiğinde, başa çıkma üzerinde olumlu temel benlik değerlendirmesinin aynı yönde anlamlı etkisinin ( $B=, 68, p<, 01)$ olduğu; işi biçimlendirme üzerinde, temel benlik değerlendirmesinin $(B=, 30$, $\mathrm{p}<, 01)$ ve başa çımanın $(\mathrm{B}=, 25, \mathrm{p}<, 01)$ aynı yönde anlamlı etkilerinin olduğu; işe tutulma üzerinde ise temel benlik değerlendirmesinin $(B=, 43, p<, 01)$, başa çımanın $(B=, 29, p<, 01)$ ve işi biçimlendirmenin $(\mathrm{B}=, 35, \mathrm{p}<, 01)$ aynı yönde anlamlı etkilerinin olduğu görülmüştür. Şekil 2 'de değişkenler üzerinde açıklanan varyans değerleri her bir değişkenin sağ üstünde belirtilmiştir. 


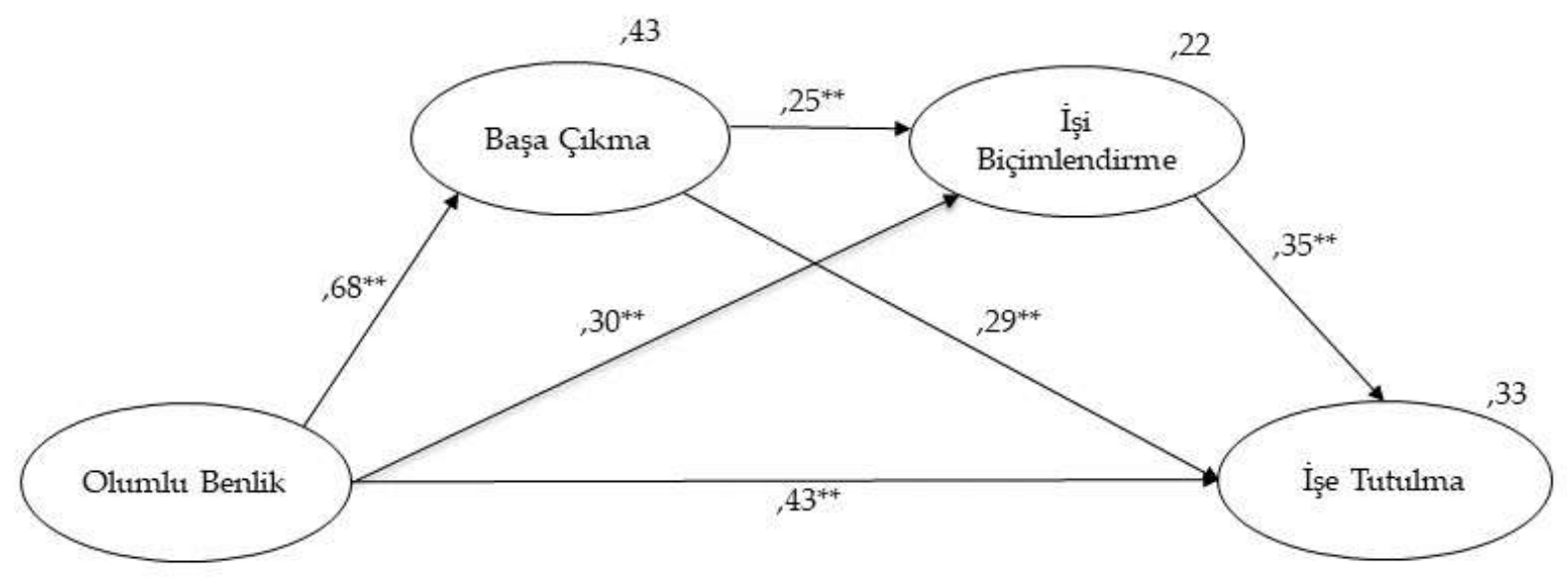

Şekil 2. Araştırma Değişkenleri Arasındaki Doğrudan Etki Değerleri

İkinci aşamada araştırmaya konu olan başa çıkmanın ve işi biçimlendirmenin aracılık rolünü incelemek amacıyla dolaylı etkilere yönelik regresyon katsayıları ve güven aralığı değerleri hesaplanmış ve elde edilen bulgular Tablo 4'de sunulmuştur. Gerek başa çıkma $(B=, 20,05<\% 95$ GA <,35), gerekse işi biçimlendirme üzerinden ( $\mathrm{B}=, 10,04<\% 95 \mathrm{GA}<, 19)$, olumlu benlik değerlendirmelerinin işe tutulma üzerindeki etkisine yönelik ayrı ayrı ve sıralı aracılık etkisinin $(B=, 06,02<\% 95 \mathrm{GA}<, 11)$, güven aralığı değerlerinin sıfırdan farklı olması incelenen dolaylı etkilerin \%95 güven aralığına göre anlamlı olduğunu göstermektedir.

Ulaşılan bulgular, olumlu temel benlik değerlendirmelerinin işe tutulma üzerindeki etkisinde başa çıkmanın ve işi biçimlendirmenin birbirinden ayrı olarak ve ikisinin birlikte anlamlı sıralı dolaylı etkilerinin olduğunu göstermiştir. Diğer bir deyişle çalışanların olumlu benlik değerlendirmelerinin işe tutulmalarını doğrudan etkilemesinin yanında başa çıkma yetkinliklerini ve işi biçimlendirmelerini de etkilediği, bu değişkenler üzerinden de işe tutulma üzerinde dolaylı etkisinin gerçekleştiği tespit edilmiştir. Elde edilen bu bulgulara göre araştırma kapsamında öne sürülen hipotezlerin tamamını destekleyen bulgular elde edildiği söylenebilir. 
Tablo 4. Aracılık (Dolaylı Etki) Analizi Sonuçları

\begin{tabular}{|c|c|c|c|c|}
\hline \multirow[b]{2}{*}{$\begin{array}{l}\text { Dolaylı Etkiler (Olumlu Benliğin İşe Tutulma üzerindeki } \\
\text { etkisinde) }\end{array}$} & \multirow[b]{2}{*}{ B } & \multirow[b]{2}{*}{ SE } & \multicolumn{2}{|c|}{$\begin{array}{l}\text { Yeniden Örnekleme } \\
\% 95 \text { GA }\end{array}$} \\
\hline & & & Alt & Üst \\
\hline Toplam Dolaylı Etki & ,36 & 08 & 21 &, 54 \\
\hline Olumlu Benlik -> Başa Çıkma -> İşe Tutulma & 20 & 08, & ,05 & ,35 \\
\hline Olumlu Benlik -> İşi Biçimlendirme -> İşe Tutulma & 10 & 04 & 04 & ,19 \\
\hline $\begin{array}{l}\text { Olumlu Benlik -> Başa Çıkma-> İşi Biçimlendirme -> İşe } \\
\text { Tutulma }\end{array}$ & 06 & 02 & ,02 & ,11 \\
\hline
\end{tabular}

$\mathrm{B}$ = standardize edilmemiş regresyon katsayısı, Alt= Alt düzey güven aralığı, Üst= Üst düzey güven aralı̆̆ı, $\mathrm{n}=276$ (5000 yeniden örnekleme)

\section{Tartışma ve Sonuç}

$\mathrm{Bu}$ çalışmada olumlu temel benlik değerlendirmelerinin işe tutulma üzerindeki etkisi ve bu etki üzerinde başa çımanın ve işi biçimlendirmenin sıralı aracılık rolü incelenmiştir. Araştırma sonucunda, olumlu temel benlik değerlendirmesinin işe tutulmayı aynı yönde doğrudan etkilediğini, ayrıca başa çıkma ve işi biçimlendirme aracılığı ile olumlu temel benlik değerlendirmesinin dolaylı olarak işe tutulma düzeyini etkilediği bulgularına ulaşılmıştır. Bu bulgular, başa çıkma kavramının İş TalepleriKaynakları Modelinde kaynakların nasıl harekete geçirildiğinin anlaşılmasına katkı sağlayabileceğini göstermektedir.

Temel benlik değerlendirmesi çalışanların sahip oldukları birçok kişisel özelliklerinin temelinde yatan bireysel kaynaklardan biridir. İş Talepleri-Kaynakları Modeli çalışanların iş talepleri karşısında yeterli kaynaklara sahip olmalarının işe tutulmalarını sağlayarak olumlu iş sonuçlarına götüreceğini öne sürmektedir (Bakker ve Demerouti, 2017; Schaufeli ve Taris, 2014; Tummers ve Bakker, 2021). Teoriyle paralel biçimde mevcut araştırma bulguları bireysel bir kaynak olan olumlu benlik değerlendirmesi düzeyinin çalışanların fiziksel bilişsel ve duygusal olarak kendilerini işlerine daha fazla vermelerini ifade eden işe tutulmayı aynı yönde etkilediğini göstermiştir. Genel öz-yeterliliği ve öz saygısı yüksek olan, kendi yaşamı çerçevesinde gelişen olaylar üzerinde kontrolünün olduğunu düşünen ve duygusal olarak dengeli olanların daha yüksek düzeyde işlerine tutulacağı söylenebilir. Bu çalışmanın diğer bir bulgusu işi biçimlendirmenin temel benlik değerlendirmesi ve işe tutulma arasında işi biçimlendirmenin anlamlı bir aracılık rolünün bulunmasıdır. Buna göre iş bireysel kaynakların düzeyi çalışanların iş ortamlarını biçimlendirebilme inisiyatifine sahip olma düzeylerini olumlu biçimde etkileyerek işe tutulmalarını artırılabilmelerine yol açmaktadır. Bu bulgunun da İş Talepleri-Kaynakları Modeli kapsamında işi biçimlendirme ile ilgili öne sürülen önceki kuramsal ve görgül çalışmalarla tutarlı olduğu görülmektedir (Bakker, Tims, Derks, 2012; Mazzetti vd., 2021; Tims ve Akkerman, 2017; Tims ve Bakker, 2010; Tims, Bakker ve Derks, 2012; Tummers ve Bakker, 2021). 
Araştırmanın diğer önemli bölümü ise teorik ve pratik uygulama açısından katkı sağlama iddiasının bulunduğu, çalışanların kişisel kaynaklarının işe tutulmalarını nasıl etkilediğinin açılanmasıyla ilgilidir. Herhangi bir araştırmaya konu olan aracılık etkisi veya aracılık rolü kavramı, incelenen bir etkinin nasıl gerçekleştiğini, bu ilişkinin altında hangi mekanizmanın olduğunu (Tabachnick ve Fidell, 2013) açıklamaya katkı sağlayan değişkenlerin ortaya çıkarılmasıyla ilgilidir. Bu araştırmada da İş Talepleri-Kaynakları Modelinde önde sürülen kaynaklar, işi biçimlendirme ve işe tutulma ilişkisinde, yazarlar tarafından başa çıkma kavramının da incelenmesinin gerektiği, kavramsal model içerisinde başaçıkmanın aracılık rolünün bulunabileceği önerilmiştir. Zira Kammayer-Mueller ve arkadaşları da (2009) temel benlik değerlendirmesi yüksek olanların etkili başa çıma yöntemlerini daha çok, etkisiz başa çıkma yöntemlerini daha az kullandıklarını ve daha az stres yaşadıklarını öne sürmektedirler. Ângelo \& Chambel'in yaptıkları araştırma sonucunda proaktif başa çıkmanın iş kaynakları ve işe tutulma arasında aracılık rolünün olduğunu göstermektedir. (Ângelo ve Chambel, 2014). Yürütülen bu çalışma sonucunda da temel benlik değerlendirmesinin bireyin algıladığı başa çıkma yetkinliğini olumlu biçimde etkilediği görülmüştür. Araştırma hipotezini destekleyen diğer bulgular ise başa çıkma düzeyinin işi biçimlendirme üzerinde doğrudan, işe tutulma üzerinde ise doğrudan ve dolaylı anlamlı etkilerin bulunmasıdır. Bu sonuçlar, iş kaynakları ile işe tutulma ilişkisinde başaçıkmanın aracılık rolünün bulunduğu Ângelo ve Chambel'in (2014) bulgularıyla tutarlıdır. Bu bulguya göre başa çıkma düzeyi arttıkça çalışanın işi biçimlendirme yönünde daha fazla inisiyatif alacağı ve bu yolla daha fazla işine tutulacağı öne sürülebilir. Nihai olarak bu bulgular birleştirildiğinde bu çalışmada başa çımanın bireysel kaynaklar-işi biçimlendirme-işe tutulma ilişkisinde aracılık rolünün olduğu ortaya çıarılmıştır. Bu bulgulara dayanılarak, çalışanların temel benlik değerlendirmeleri gibi eylemlerinde kendine güç sağlayan bireysel kaynaklarının düzeyinin fazla olması onların karşılaştıkları olayların üstesinden gelme yetkinliklerini artıracağı söylenebilir. Karşılaştığı olaylarla başa çıkabileceğini değerlendiren çalışanların, iş bağlamlarını kendilerine uygun biçimde değiştirme ve biçimlendirmeye daha çok meyilli olacakları ileri sürülebilir. İşlerini kendi inisiyatifleriyle en iyi şekilde gerçekleştirebileceği biçimde düzenleyebilmeleri ve biçimlendirebilmeleri sonucunda ise çalışanların işlerine daha fazla tutulacakları söylenebilir.

Mevcut çalışmanın özellikle bireysel kaynakların işi biçimlendirmeyi nasıl etkilediğine dair anlayışımızı başa çıkmanın aracılık rolünü ortaya çıkararak geliştirebileceği düşünülmektedir. Kaynaklara sahip olmak bu kaynakların doğrudan kullanılacağını göstermeyebilir. Çalışanların karşılaştıkları iş taleplerinin üstesinden gelebileceklerine dair bireysel algılarının düzeyine göre sahip oldukları kaynakları kullanmaya başladıkları ve iş bağlamını uygun biçimde şekillendirebildikleri ve işlerine tutulabildikleri anlaşılmaktadır. Bu anlayışın kavramsal olarak İş Talepleri-Kaynakları Modelinin daha geniş olarak düşünülmesine yönlendirmenin yanında uygulama açısından bazı önerileri de gündeme getirmektedir. Çalışanların iş taleplerini karşılamayabilecekleri kişisel ve örgütsel

| 1750 | kaynaklarının düzeyini artırmanın olumlu sonuçlarının olabileceğinin yanı sıra daha da önemli bir konu olarak mevcut kaynakların talepleri karşılamak için daha iyi nasıl kullanılabileceğinin çalışanlar arasında yaygın biçimde bilinmesi başa çıkma yetkinliğini ve buna bağlı olarak iş biçimlendirme ve işe tutulma düzeyleri artırabileceği öne sürülebilir. Bu araştırmada elde edilen bulguların ve bunlara dayanılarak 
yapılan değerlendirme ve önerilerin, İş Talepleri-Kaynakları Modelinin kuramsal gelişimine ve aynı zamanda uygulamaya katkı sağlayabileceği değerlendirilmektedir.

Son olarak araştırmada elde edilen bulgularının genellenebilirliğinin örneklemin büyüklügüyle sınırlı olduğu göz önünde bulundurulmalıdır. Bu çalışmada önerilen teorik genellemelerin yapılabilmesi için daha kapsamlı örneklemlerle ve farklı kültürel çevrelerde bu çalışmadaki araştırma modelinin araştırılmasına, ilaveten doğrulanmasına ihtiyaç bulunmaktadır. Ayrıca, kullanılan kesitsel veri toplama tekniği nedensel ilişkilerin yönünün teorik gerekçelere dayandırılmasına zorlamaktadır. Gelecekte yapılacak çalışmalarda İş Talepleri - Kaynakları Modeli kapsamında farklı başa çıkma yöntemleri ve farklı işi biçimlendirme yolları arasındaki ilişkilerin ortaya çıkarılabileceği araştırma tasarımlarının yapılması önerilmektedir.

\section{Etik Beyanı}

Yazarlar çalışmanın bilimsel araştırma etik ilkelerine uyularak yürütülmüş̧ olduğunu beyan eder. Araştırmanın katılımcıları çalışma hakkında bilgilendirilerek, gönüllülük esasına göre anonim olarak çalışmaya katılmıştır.

\section{Katkı Oranı Beyanı}

Yazarlar makaleye eşit oranda katkı sağlamış olduklarını beyan eder.

\section{Çıkar Çatışması Beyanı}

Makale yazarları aralarında herhangi bir çıkar çatışması olmadığını beyan eder.

\section{Destek ve Teşekkür Beyanı}

Bu çalışma herhangi bir organizasyondan destek almadan yürütülmüştür.

$$
\text { 战淡 }
$$




\section{Kaynakça}

Ângelo, R. P., \& Chambel, M. J. (2014). The role of proactive coping in the Job Demands-Resources Model: A cross-section study with firefighters. European Journal of Work and Organizational Psychology, 23(2), 203-216. https://doi.org/10.1080/1359432X.2012.728701

Bakker, A. B., \& Demerouti, E. (2007). The Job Demands-Resources model: State of the art. Journal of Managerial Psychology, 22, 309-328.

Bakker, A. B., \& Demerouti, E. (2017). Job demands-resources theory: Taking stock and looking forward. Journal of Occupational Health Psychology, 22(3), 273-285.Bakker, A. B., Tims, M., \& Derks, D. (2012). Proactive personality and job performance: The role of job crafting and work engagement. Human Relations, 65 (10), 1359-1378.

Baltaş Z., Atakuman, Y. \& Duman, Y. (1998) Standardization of the Perceived Stress Scale: Perceived stress in middle managers. Stress and Anxiety Research Society 19 the International Conference. Boğaziçi University, İstanbul, July 10-12.

Bipp, T., Kleingeld, A., \& Ebert, T. (2019). Core self-evaluations as a personal resource at work for motivation and health. Personality and Individual Differences, 151, 109556.

Cohen, S., Kamarck, T., \& Mermelstein, R. (1983). A global measure of perceived stress. Journal of Health and Social Behavior, 24 (4), 385-396.

Crawford, E. R., LePine, J. A., \& Rich, B. L. (2010). Linking job demands and resources to employee engagement and burnout: A theoretical extension and meta-analytic test. Journal of Applied Psychology, 95, 834-848.

Eryılmaz, E., \& Doğan, T. (2012). İş yaşamında öznel iyi oluş: Utrecht İşe Bağlllık Ölçeğinin psikometrik niteliklerinin incelenmesi, Klinik Psikiyatri, 15, 49-55.

Eskin, M., Harlak, H., Demirkıran, F. \& Dereboy, Ç. (2013). Algılanan Stres Ölçeğinin Türkçeye Uyarlanması: Güvenirlik ve Geçerlik Analizi. New/Yeni Symposium Journal, 51(3), 132-140.

Güler, M., Çetin, F. \& Basım, H. N. (2019) İşe Tutulma Ölçeği çok kısa versiyonu (UWES-3) geçerlilik ve güvenilirlik çalışması: Alternatif bir versiyon (UWES-6) önerisi, İş ve İnsan Dergisi, 6(2), 187-195.

Hu, L. \& Bentler, P.M. (1999). Cutoff criteria for FIT indexes in covariance structure analysis: conventional criteria versus new alternatives, SEM. 6 (1), 1-55.

Jones, F. \& Bright, J. (2001) Stress Myth, Theory and Research, Pearson.

| 1752 | Judge, T. A., Erez, A., Bono, J. E., \& Thoresen, C. J. (2003). The core self-evaluations scale: Development of a measure, Personnel Psychology, 56, 303-331.

Kahn, W. A. (1990). Psychological conditions of personal engagement and disengagement at work. Academy of Management Journal, 33, 692-724. 
Kammeyer-Mueller, J. D., Judge, T. A., \& Scott, B. A. (2009). The role of core self-evaluations in the coping process. Journal of Applied Psychology, 94(1), 177-195. https://doi.org/10.1037/a0013214

Lazarus, R. S. (1993). From psychological stress to the emotions: A history of changing outlooks, Annual Review of Psychology, 44, 1-21.

Lichtenthaler, P. W. \& Fischbach, A. (2019). A meta-analysis on promotion- and prevention-focused job crafting, European Journal of Work and Organizational Psychology, 28(1), 30-50.

Mazzetti, G., Robledo, E., Vignoli, M., Topa, G., Guglielmi, D., \& Schaufeli, W. B. (2021). Work Engagement: A meta-Analysis Using the Job Demands-Resources Model. Psychological Reports, 003329412110519. https://doi.org/10.1177/00332941211051988

Örücü, M. Ç. ve Demir, A. (2009). Psychometric evaluation of perceived stress scale for Turkish university students, Stress and Health, 25(1), 103-109.

Özkalp, E. \& Meydan, B. (2015). Schaufeli ve Bakker tarafından geliştirilmiş olan İşe Angaje Olma Ölçeğinin Türkçe'de güvenilirlik ve geçerliliğinin analizi, İş, Güç Endüstri İlişkileri ve İnsan Kaynakları Dergisi, 17(3), 04-19.

Preacher, K. J. \& Hayes, A. F. (2008). Asymptotic and resampling strategies for assessing and comparing indirect effects in multiple mediator models. Behavior Research Methods. 40, 879-91.

Rich, B. L., Lepine, J. A. \& Crawford, E. R. (2010). Job engagement: Antecedents and effects on job performance, Academy of Management Journal, 53(3), 617-635.

Searle, B. J., \& Lee, L. (2015). Proactive coping as a personal resource in the expanded job demandsresources model. International Journal of Stress Management, 22(1), 46-69.

Shrout, P. E. \& Bolger, N. (2002). Mediation in experimental and nonexperimental studies: New procedures and recommendations. Psychological Methods. 7, 422-45.

Slemp, G. R., \& Vella-Brodrick, D. A. (2013). The Job Crafting Questionnaire: A new scale to measure the extent to which employees engage in job crafting. International Journal of Wellbeing, 3(2), 126-146.

Schaufeli, W. B., \& Bakker, A. B. (2004). Job demands, job resources, and their relationship with burnout and engagement: A multi-sample study. Journal of Organizational Behavior, 25, 293-315.

Schaufeli, W. B., Bakker, A. B. \& Salanova, M. (2006). The Measurement of work engagement with a short questionnaire A Cross-National Study. Educational and Psychological Measurement. 66(4), 701-716.

Schaufeli, W.B. \& Taris, T.W. (2014). A critical review of the Job Demands-Resources Model: Implications for improving work and health. In G. Bauer \& O. Hämmig (Eds), Bridging occupational, organizational and public health. Springer. 43-68.

Şeşen, H. (2010). Öncülleri ve sonuçlarn ile örgüt içi girişimcilik: Türk Savunma Sanayinde bir araştırma. Doktora Tezi. Kara Harp Okulu, Savunma Bilimleri Enstitüsü. 
Tabachnick, B. G., \& Fidell, L. S. (2013). Using Multivariate Statistics, Pearson.

Taris, T.W. \& Schaufeli, W.B. (2016). The Job Demands-Resources model. In: S. Clarke, T.M. Probst, F. Guldenmund \& J. Passmore (Eds.). The Wiley Blackwell handbook of the psychology of occupational safety and workplace health. John Wiley. pp.157-180.

Tims M, \& Akkermans J (2017) Core self-evaluations and work engagement: Testing a perception, action, and development path. PLOS ONE, 12(8), e0182745.

Tims, M. \& Bakker, A.B. (2010), Job crafting: towards a new model of individual job redesign, South African Journal of Industrial Psychology, 36 (2), 1-9.

Tims, M., Bakker, A.B. \& Derks, D. (2012), Development and validation of the job crafting scale", Journal of Vocational Behavior, 80 (19), 173-186.

Tims, M., B. Bakker, A. and Derks, D. (2014), Daily job crafting and the self-efficacy - performance relationship", Journal of Managerial Psychology, 29(5), 490-507. https://doi.org/10.1108/JMP-05-20120148 .

Tummers, L. G., \& Bakker, A. B. (2021). Leadership and Job Demands-Resources Theory: A Systematic Review. Frontiers in Psychology, 12, 4149. https://doi.org/10.3389/fpsyg.2021.722080

Weiss, H. M., \& Cropanzano, R. (1996). Affective Events Theory: A theoretical discussion of the structure, causes and consequences of affective experiences at work. In B. M. Staw \& L. L. Cummings (Eds.), Research in organizational behavior: An annual series of analytical essays and critical reviews, 18, (1-74). Elsevier Science/JAI Press.

Wrzesniewski, A. \& Dutton, J. E. (2001), Crafting a Job: Revisioning Employees as Active Crafters of Their Work, The Academy of Management Review, 26(2), 179-201.

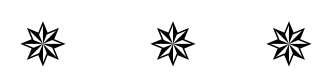

